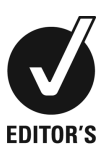

CHOICE

\title{
Acute unilateral isolated ptosis
}

\author{
Jennifer Helen Court, ${ }^{1,2}$ David Janicek ${ }^{1}$
}

${ }^{1}$ Department of Ophthalmology, Singleton Hospital, Swansea, UK

${ }^{2}$ Home, Swansea, UK

Correspondence to Jennifer Helen Court, jenjohnston1@hotmail.com

Accepted 19 December 2014

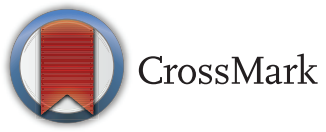

To cite: Court JH, Janicek D. BMJ Case Rep Published online: [please include Day Month Year] doi:10.1136/bcr-2014207720

\section{SUMMARY}

A 64-year-old man presented with a 2-day history of acute onset painless left ptosis. He had no other symptoms; importantly pupils were equal and reactive and eye movements were full. There was no palpable mass or swelling. He was systemically well with no headache, other focal neurological signs, or symptoms of fatigue. CT imaging showed swelling of the levator palpebrae superioris suggestive of myositis. After showing no improvement over 5 days the patient started oral prednisolone $30 \mathrm{mg}$ reducing over 12 weeks. The ptosis resolved quickly and the patient remains symptom free at 6 months follow-up. Acute ptosis may indicate serious pathology. Differential diagnoses include a posterior communicating artery aneurysm causing a partial or complete third nerve palsy, Horner's syndrome, and myasthenia gravis. A careful history and examination must be taken. Orbital myositis typically involves the extraocular muscles causing pain and diplopia. Isolated levator myositis is rare.

\section{BACKGROUND}

Acute ptosis may indicate a serious underlying pathology and a careful history and examination must be taken to inform decisions on the type and urgency of appropriate investigations and treatment.

\section{CASE PRESENTATION}

A 64-year-old man was referred to the emergency eye clinic by his optician with a 2-day history of acute onset painless left ptosis. He did not report any double vision, blurred vision or headache. $\mathrm{He}$ had woken with the ptosis and it had not improved or worsened over the 2 days, with no history of fatiguability or variability. Prior to this he had not had any eye problems and was not a contact lens wearer. His medical history included cardiomyopathy and arrythmogenic right ventricular tachycardia for which he had an implantable cardioverter defibrillator (ICD) fitted and was awaiting ablation. He felt fit and well, with no preceding viral illness, no headache, and no symptoms of malaise or fatigue. He was without fever.

On examination the palpebral aperture measured $6 \mathrm{~mm}$ on the right and $2 \mathrm{~mm}$ on the left. The superior margin-reflex distance was $2 \mathrm{~mm}$ on the right and $-1 \mathrm{~mm}$ on the left. Levator function measured $13 \mathrm{~mm}$ bilaterally.

Apart from its position the lid was normal in appearance with no mechanical cause for the ptosis such as swelling, palpable mass or subtarsal abnormality. The lid crease height was normal at $8 \mathrm{~mm}$ and symmetrical bilaterally, with no evidence of aponeurosis dis-insertion. Visual acuity was normal at $0.1 \log$ MAR each eye and pupils were equal in bright and dim light and reactive to light and accommodation. Cover test showed no deviation and eye movements were full with no diplopia elicited. There was no proptosis and both eyes were white and quiet with normal symmetrical intraocular pressures and healthy funduscopy. Cranial nerve examination was normal.

\section{INVESTIGATIONS}

The patient underwent blood tests, with normal full blood count, urea and electrolytes, liver function tests, thyroid function tests, glucose, lipids, C reactive protein and erythrocyte sedimentation rate. Autoimmune screen was normal including thyroid antibodies, antineutrophil cytoplasmic antibody and antinuclear antibody. Serum ACE was normal and acetylcholine receptor antibodies were negative. An orthoptic assessment and HESS chart confirmed the above findings with full eye movements and an isolated ptosis.

An urgent CT angiogram was requested to rule out the possibility of a posterior communicating artery aneurysm (MRI was contraindicated because of his ICD). This showed a normal cerebral appearance, no retro-orbital mass and no aneurysm. There was ill-defined enlargement of superior rectus with mild thickening of adjacent levator palpabrae superioris, with stranding of fat around the left superior rectus to the upper border of the lateral rectus. The remainder of the extraocular muscles were normal, with no optic nerve compression, no dilation of the superior ophthalmic veins and symmetrical cavernous sinuses. These finding were in keeping with an inflammatory process of the superior rectus and levator palpabrae superioris. Involvement of the whole muscles without tendon sparing suggested orbital myositis rather than thyroid eye disease (figure 1A, B CT scan at presentation).

\section{DIFFERENTIAL DIAGNOSIS}

This presentation of isolated unilateral ptosis was not typical of a neurogenic cause. A partial third cranial nerve palsy would typically involve the superior, inferior and medial recti to some degree causing diplopia. Compressive lesions, including a posterior communicating artery aneurysm, classically involve the pupillary fibres which are most vulnerable to compression in their location at the periphery of the third nerve, and cause pupil dilation. However, pupil sparing, as in this case, is not a reliable sign and an aneurysm must be considered and excluded. The typical associated headache may also be absent. The most common cause of a partial third nerve palsy is microvascular and is associated with diabetes mellitus, hypertension, 

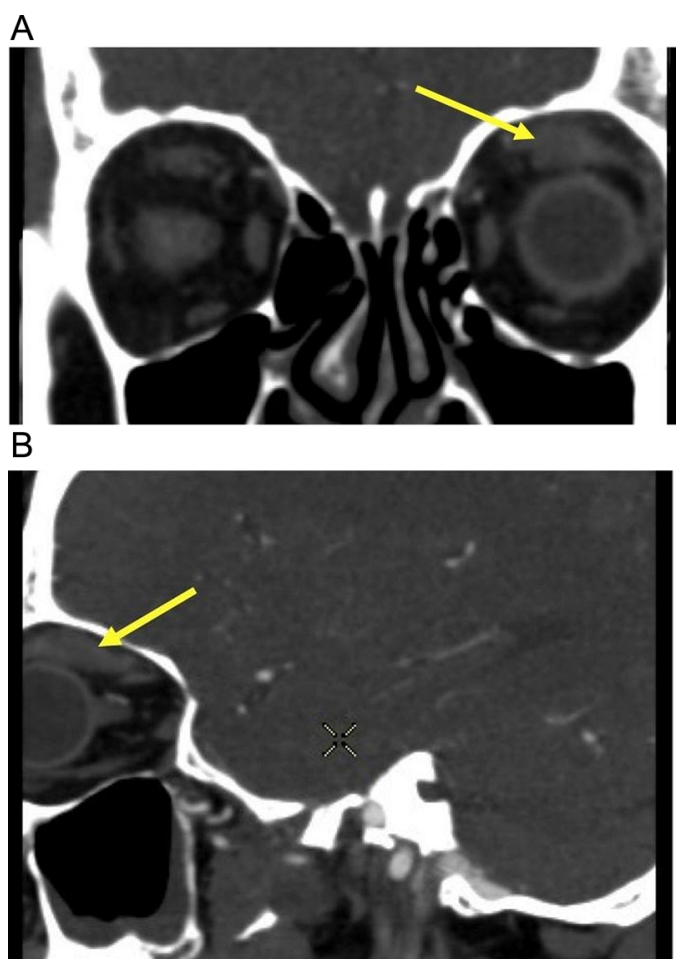

Figure 1 (A and B) CT scan at presentation.

dyslipidaemia and smoking. There are however case reports of isolated ptosis caused by aneurysmal compression ${ }^{1-3}$ so this must be investigated appropriately.

Horner's syndrome usually causes a smaller ptosis and the pupil will be constricted. This can be subtle and must be carefully examined. The diagnosis can be confirmed with pharmacological testing with topical apraclonidine, causing dilation of the affected pupil due to denervation hypersensitivity of the iris dilator muscle.

Myogenic causes of ptosis include myasthenia gravis. Absence of variability, fatiguability and Cogan's twitch sign, as well as the isolated acute onset make this less likely. The patient may not exhibit symptoms of systemic muscle fatigue if they have ocular myesthenia but variable diplopia is often present. Negative acetylcholine receptor antibodies does not exclude the diagnosis. Ptosis may be asymmetric but is usually bilateral.

Miller-Fischer syndrome and Guillain-Barre syndrome may initially present with ptosis following a preceding illness but there would be progressive signs.

Orbital infection is an important differential of orbital myositis, and patients presenting with more diffuse symptoms and signs are commonly treated with intravenous antibiotics and closely monitored before the diagnosis of idiopathic orbital inflammation is made. However, in this systemically well patient with absent orbital signs, no erythema, pain or swelling and normal blood markers we did not feel treatment with intravenous antibiotics was indicated at presentation. Given the CT scan findings and the absence of progression of his symptoms in the 5 days from onset to starting steroids we felt the diagnosis of infection was very unlikely and did not warrant further investigation.

\section{TREATMENT}

After showing no improvement over 5 days and in view of the CT scan result, the patient was started on $30 \mathrm{mg}$ oral prednisolone reducing to $20 \mathrm{mg}$ after 1 week. The ptosis resolved and steroids were slowly reduced and stopped over the following 8 weeks.
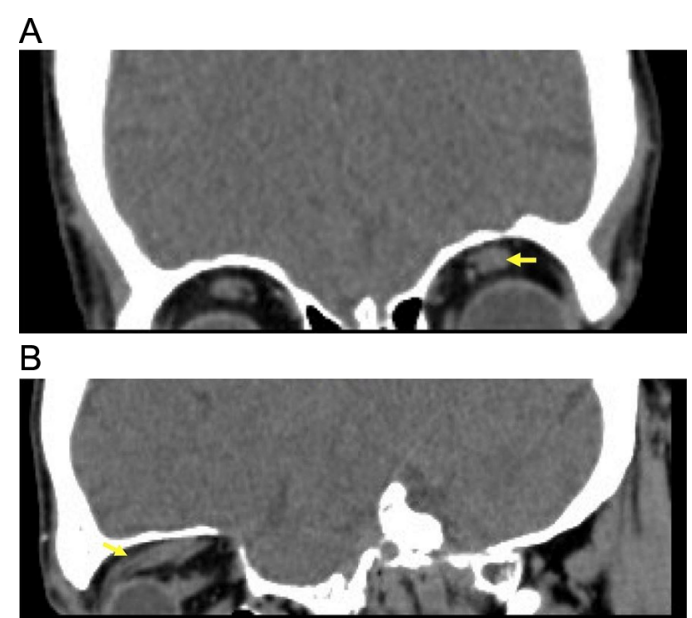

Figure 2 (A and B) follow-up CT scan.

\section{OUTCOME AND FOLLOW-UP}

The patient remains symptom free at 6 months follow-up. A CT head scan performed for a non-related presentation 6 months later shows the size of the superior rectus and levator palpabrae superioris to be returning to normal (figure 2A, B follow-up CT scan).

\section{DISCUSSION}

Orbital myositis is a subtype of non-specific inflammation of the orbit primarily involving the extraocular muscles. It most commonly affects young to middle-aged adults with a female predominance. $^{4-6}$

Patients typically present with orbital pain exacerbated by eye movement, with conjunctival injection over the affected muscle, oedema, diplopia due to impaired function of the inflamed extraocular muscle and in some cases mild proptosis.

It is usually acute and unilateral and most commonly affects the medial recti, followed by the superior and lateral recti and rarely the obliques and inferior recti. ${ }^{7}$ While ptosis is not uncommonly seen as part of orbital myositis, an isolated presentation of ptosis caused by myositis of the levator palpabrae superioris has only rarely and briefly been described in the literature. ${ }^{8-12}$ Reduced levator function and lid lag on down-gaze has been reported but these were not a feature in this case. ${ }^{8} 10$ Lid swelling was also a reported feature that was absent in this case, ${ }^{9} 1012$ as was discomfort or pain. ${ }^{10-12}$

In this case the CT scan showed involvement of the superior rectus but function was not impaired on examination. Siatkowski et $a l^{13}$ reviewed 75 patients with orbital myositis and found the function of the extraocular muscles affected changed over the course of the disease. In the first 10 days the extraocular muscle function was normal, followed by a paretic phase from day 11 to 14 , and a restrictive or mixed phase which partially or completely resolves from day 17 to 24 . Our patient presented early in the disease process which likely explains the normal function of the superior rectus. The most common differential diagnosis for orbital myositis is thyroid eye disease. Imaging modalities include ultrasonography, CT and T2-weighted MRI, showing enlarged muscle bellies with thickened tendons (vs tendon sparing in thyroid eye disease), with low internal reflectivity on ultrasound and enhancement with contrast on $\mathrm{CT}^{8}$ and MRI. ${ }^{11}$

Treatment with systemic corticosteroids is the mainstay of therapy, with rapid resolution of symptoms, ${ }^{4}{ }^{6}$ although spontaneous remission may occur, and in two of the previous case reports the ptosis resolved without treatment. ${ }^{10}{ }^{11}$ Some cases 
of orbital myositis however become refractory and may require repeated courses of steroid treatment, radiotherapy or immunosuppressive agents. Further investigations to exclude other inflammatory, neoplastic, vasculitic or infectious conditions are advised in this situation. ${ }^{4} 6$

\section{Patient's perspective}

As indicated in the piece, prior history of illness is important, in my case ventricular tachycardia. The initial symptoms I experienced made me anxious that I may have had a stroke. I am grateful therefore for the prompt action of the consultant in arranging a CT scan within 2 days, thus lessoning my anxiety.

\section{Learning points}

- In all cases of ptosis the pupils and eye movements must be carefully examined.

- Painless isolated ptosis should lead to consideration of serious life-threatening disorders with timely and appropriate investigations before diagnosing orbital myositis.

- Orbital myositis is an idiopathic inflammatory condition diagnosed by history, examination and appropriate imaging. Oral steroids are the mainstay of treatment.

- Orbital myositis is a rare cause of isolated ptosis but should be considered in the differential diagnosis in the absence of pupil abnormalities and confirmed with appropriate investigations.
Acknowledgements The authors would like to thank Dr Rachel Smith, Consultant Radiologist.

Competing interests None.

Patient consent Obtained.

Provenance and peer review Not commissioned; externally peer reviewed.

\section{REFERENCES}

1 Good EF. Ptosis as the sole manifestation of compression of the oculomotor nerve by an aneurysm of the posterior communicating artery. I Clin Neuroophthalmol 1990;10:59-61.

2 Tummala R, Harrison A, Madison MT, et al. Pseudomyesthenia resulting from a posterior carotid artery wall aneurysm: a novel presentation: case report. Neurosurg 2001;49:1466-9.

3 Fukushima $\mathrm{Y}$, Imai $\mathrm{H}$, Yoshino $\mathrm{M}$, et al. Ptosis as partial oculomotor nerve palsy due to compression by infundibular dilatation of posterior communicating artery, visualised by three-dimensional computer graphics: case report. Neurol Med Chir (Tokyo) 2014;54:214-18

4 Costa RM, Dumitrascu OM, Gordon LK. Orbital myositis: diagnosis and management. Curr Allergy Asthma Rep 2009;9:316-23.

5 Scott IU, Siatkowski RM. Idiopathic orbital myositis. Curr Opin Rheumatol 1997:9:504-12

6 Dubey A, Eidsness R, Koul R. Idiopathic orbital myositis and review of literature. Internet J Ophthal Vis Sci 2009;8

7 Trokel SL, Hilal SK. Recognition and differential diagnosis of enlarged extra ocular muscles in computed tomography. Am J Ophthalmol 1979:87:503-12.

8 Rice CD, Gray LD. Isolated levator myositis. Ophthal Plast Reconstr Surg 1988;4:167-70.

9 Umehara F, Tokimura Y, Osame M. Acute isolated levator palpebral myositis. Rinsho Shinkeigaku 1998;38:63-5.

10 Wheatcroft $\mathrm{S}$, Elston J. Unilateral ptosis due to isolated involvement of the levator muscle in acute orbital myositis. Br J Ophthalmol 1999;83:631-2.

11 Almekhlafi MA, Fletcher WA. Levator palpebrae myositis. Neurology 2008;71:1202

12 Yoon JH, Moon HS, Chi M. Unilateral ptosis due to isolated levator myositis. J Korean Ophth Soc 2012;53:707-11.

13 Siatkowski RM, Capo H, Byrne SF, et al. Clinical and echographic findings in idiopathic orbital myositis. Am J Ophthalmol 1994;118:343-50.

Copyright 2015 BMJ Publishing Group. All rights reserved. For permission to reuse any of this content visit http://group.bmi.com/group/rights-licensing/permissions.

BMJ Case Report Fellows may re-use this article for personal use and teaching without any further permission.

Become a Fellow of BMJ Case Reports today and you can:

- Submit as many cases as you like

- Enjoy fast sympathetic peer review and rapid publication of accepted articles

- Access all the published articles

Re-use any of the published material for personal use and teaching without further permission

For information on Institutional Fellowships contact consortiasales@bmjgroup.com

Visit casereports.bmj.com for more articles like this and to become a Fellow 